\title{
Effect of protein and lactulose on the production of $\gamma$-aminobutyric acid by faecal Escherichia coli
}

\author{
H Al Mardini, B Al Jumaili, C O Record, D Burke
}

\begin{abstract}
The value of lactulose treatment in hepatic encephalopathy is widely recognised but its mode of action remains controversial. Much evidence supports a role for $\gamma$-aminobutyric acid in hepatic encephalopathy, and lactulose could alter its bacterial production in the gut. Using the rat synaptic membrane assay and gas chromatography mass spectrometry, the production of $\gamma$-aminobutyric acid by faecal Escherichia coli, with and without the addition of albumin, haemoglobin, whole blood, and lactulose under aerobic and anaerobic conditions was determined. Using an inorganic medium, maximal $\gamma$-aminobutyric acid production occurred after a culture period of between 25 and 50 hours. The concentration after 30 hours of aerobic culture at $37^{\circ} \mathrm{C}$ by a single strain was mean (SEM), 101 (5) $\mu \mathrm{mol} / 1$ (99\% confidence intervals $87-114 \mu \mathrm{mol} / 1 ; n=8$; interassay coefficient of variation $14 \cdot 7 \%$ ). $\gamma$ aminobutyric acid production was significantly increased by the addition of albumin and haemoglobin. Under anerobic conditions, it was one fifth of that produced aerobically, but the addition of albumin and haemoglobin increased production by $>700 \%$. Lactulose did not significantly attenuate $\gamma$-aminobutyric acid production under aerobic or anaerobic conditions. $\gamma$-aminobutyric acid determined by the rat synaptic membrane assay showed a highly significant correlation $(r=0.99)$ with that detected by gas chromatography mass spectrometry. These data confirm that $\gamma$-aminobutyric acid is produced by faecal $E$ coli and that protein enhances its production considerably, and suggest that lactulose does not exert its therapeutic effect by attenuating $\gamma$ aminobutyric acid production.
\end{abstract}

Cerebrotoxic substances derived from the gut are thought to be involved in the mediation of hepatic encephalopathy. Treatments shown to benefit this disorder are thought to act by an effect on colonic bacterial metabolism. Although lactulose has been used since $1966^{\prime}$ in the treatment of hepatic encephalopathy, its mode of action remains controversial. Proposed mechanisms include acidification of the colon, ${ }^{2}$ decrease in ammonia production, ${ }^{3}$ normalisation of the fatty acid profile, ${ }^{+}$or merely as a purgative.

$\gamma$-aminobutyric acid is the predominant neuroinhibitory neurotransmitter in the mammalian brain and recent interest has highlighted it as a candidate mediator of hepatic encephalopathy. ${ }^{5}$ Raised values of $\gamma$-aminobutyric acid like activity have been found in the plasma of patients with liver disease ${ }^{67}$ and in experimental animals. ${ }^{8}$ $\gamma$-aminobutyric acid arising in the gut is thought to cross the blood brain barrier because of the defective blood brain permeability that has previously been shown in a rabbit galactosamine model of hepatic encephalopathy. ${ }^{9}$

Schafer et $a l^{10}$ showed that faecal bacteria are capable of producing $\gamma$-aminobutyric acid like substances in vitro and suggested that the colonic flora were the source of the $\gamma$-aminobutyric acid like activity detected in the blood. Other workers ${ }^{11}$ have suggested that the bowel mucosa itself contributes to $\gamma$-aminobutyric acid like activity detected in the portal blood. Gastrointestinal bleeding and high protein diets are potent precipitations of hepatic encephalopathy and it is thought that the resulting modulation of colonic bacterial metabolism may lead to the production of cerebrotoxic substances.

The aims of this study were to examine the production of $\gamma$-aminobutyric acid by faecal Escherichia coli, determine the effect of protein on its production, and to assess whether lactulose exerts its beneficial effect by attenuating $\gamma$ aminobutyric acid production.

\section{Methods}

Faecal $E$ coli were isolated from normal controls and stored on nutrient agar slopes. Ten strains of the isolated $E$ coli were cultured separately for 18 hours at $37^{\circ} \mathrm{C}$ in tryptic soya broth in order to determine the amount of $\gamma$-aminobutyric acid like activity produced by each strain. The strain that produced the highest amount was chosen for further study.

To determine the most suitable growth medium, the selected strain of $E$ coli was grown under aerobic conditions at $37^{\circ} \mathrm{C}$ for 18 hours in different liquid culture media, brain heart infusion broth, proteose peptone No 3 (Difco), casamino acid yeast extract medium, tryptone soya broth, and a synthetic non-organic medium $\left(\mathrm{NaCl} 5 \cdot 5 \mathrm{~g} / \mathrm{l} ; \mathrm{KCl} 3 \cdot 7 \mathrm{~g} / \mathrm{l} ; \mathrm{CaCl}_{2} 0 \cdot 15 \mathrm{~g} / \mathrm{l} ; \mathrm{MgCl}_{2}\right.$ $0.1 \mathrm{~g} / \mathrm{l} ; \mathrm{NH}_{4} \mathrm{SO}_{4} 1.5 \mathrm{~g} / \mathrm{l} ; \mathrm{K}_{2} \mathrm{PO}_{4} 0 \cdot 27 \mathrm{~g} / \mathrm{l}$; glucose $10 \cdot 0 \mathrm{~g} / 1$; Tris buffer $12 \cdot 1 \mathrm{~g} / \mathrm{l} ; \mathrm{pH} 7 \cdot 4$ ).

INCUBATION OF E COLI WITH WHOLE BLOOD, ALBUMIN, HAEMOGLOBIN, AND LACTULOSE

The effect of adding protein to the culture media was studied by incubating $E$ coli alone and together with whole blood $(0.5 \mathrm{ml} / 10 \mathrm{ml})$, haemoglobin $(60 \mathrm{mg} / 10 \mathrm{ml})$, or albumin $(120 \mathrm{mg} /$ $10 \mathrm{ml}$ ). Lactulose was added to the culture medium alone at concentrations of 25,50 , and $100 \mathrm{mmol} / \mathrm{l}$, and together with albumin $(120 \mathrm{mg} /$ $10 \mathrm{ml}$ ) at a concentration of $100 \mathrm{mmol} / \mathrm{l}$ (all substrates were added to the culture medium immediately before incubation). Media with and without the various additives were incubated in the absence of $E$ coli as controls. 
$E$ coli were grown both aerobically in a shaking water bath at $37^{\circ} \mathrm{C}$ and in an anaerobic cabinet at $37^{\circ} \mathrm{C}$. At the end of the culture period viable counts were determined by the method of Miles and Misra. ${ }^{12}$ The remaining culture medium was centrifuged at $3000 \mathrm{~g}$ at $4^{\circ} \mathrm{C}$ and aliquots of supernatant stored at $-20^{\circ} \mathrm{C}$ pending analysis of $\mathrm{pH}$ and concentrations of $\gamma$-aminobutyric acid, glucose, and lactulose. The lactulose concentration was determined by gas liquid chromatography by the method of Laker. ${ }^{13}$

\section{$\gamma$-AMINOBUTYRIC ACID ANALYSIS}

$\gamma$-aminobutyric acid like activity was measured by a radioreceptor assay using rat synapatic membranes and radiolabelled $\gamma$-aminobutyric acid as described by Enna $e t a l^{14}$ and Ferkany $e t$ $a l .{ }^{15}$ Samples were assayed in triplicate and residual radioactivity assessed using a $\beta$ liquid scintillation counter. The concentration of true $\gamma$-aminobutyric acid was also determined by gas chromatography mass spectrophotometry using a Finnigan Mat 1020 based on the method described by Moroni et $a l^{16}$ and Levy et $a l .{ }^{17} \mathrm{~A}$ DB5 (30 m $\times 2.5 \mathrm{~mm}$ internal diameter) gas chromatography column was used with an initial column temperature of $80^{\circ} \mathrm{C}$ for two minutes. The final temperature of $260^{\circ} \mathrm{C}$ for five minutes was achieved by increasing the temperature by $8^{\circ} \mathrm{C}$ per minute.

\section{STATISTICAL ANALYSIS}

The results of $\gamma$-aminobutyric acid obtained by the two techniques were expressed as mean (SEM) and the statistical differences between the groups were assessed using unpaired Student's $t$ test (two tailed). Linear regression analysis was used to determine the correlation between $\gamma$-aminobutyric acid concentrations measured by the radioreceptor assay and by gas chromatography mass spectrophotometry.

\section{Results}

EFFECT OF DIFFERENT CULTURE MEDIA AND LENGTH OF INCUBATION ON THE PRODUCTION OF $\gamma$-AMINOBUTYRIC ACID LIKE ACTIVITY

Table I shows the background $\gamma$-aminobutyric acid like activity found in the culture media used. Because all four standard media contained detectable amounts of $\gamma$-aminobutyric acid like activity, the non-organic medium, which showed no background activity, was chosen for use in future studies. The mean $\gamma$-aminobutyric acid like activity found after 30 hours aerobic $E$ coli culture in this medium at $37^{\circ} \mathrm{C}$ was $101(5)$

TABLE I Background $\gamma$-aminobutyric acid (GABA) found in the culture medium used

\begin{tabular}{ll}
\hline Media tested & $\begin{array}{l}\text { Concentrations of GABA like } \\
\text { activity detected }\end{array}$ \\
\hline Brain heart infusion broth & $>5$ mmol GABA equiv/l \\
Proteose peptone no 3 & $>5$ mmol GABA equiv/1 \\
Casamino acid yeast extract & $>5$ mmol GABA equiv/1 \\
Tryptone soya broth & $>200$ mmol GABA equiv/l \\
Non-organic medium & Undetectable \\
\hline
\end{tabular}

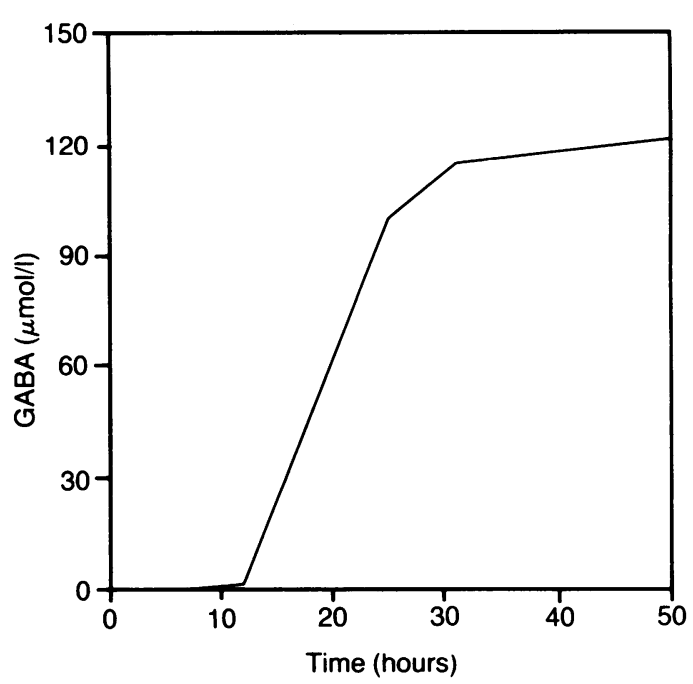

Figure 1: Production of $\gamma$-aminobutyric acid (GABA) like activity by Escherichia coli during culture under aerobic conditions. Each point represents the mean of four separate experiments.

$\mu \mathrm{mol} / \mathrm{l} \quad(\mathrm{n}=8)$. The interassay coefficient of variation was $14 \cdot 7 \%$. $\gamma$-aminobutyric acid like activity was detectable in small amounts after two to 12 hours incubation (Fig 1), while there was an exponential increase from $1 \cdot 2 \mu \mathrm{mol} / \mathrm{l}$ at 12 hours to $100 \mu \mathrm{mol} / \mathrm{l}$ at 25 hours. Thereafter, there was only a slight increase until the end of the incubation period ( 50 hours). Based upon these observations, a 30 hour incubation period at $37^{\circ} \mathrm{C}$ was used in the following studies.

\section{PRODUCTION OF $\gamma$-AMINOBUTYRIC ACID LIKE} ACTIVITY UNDER AEROBIC CONDITIONS

The different concentrations of lactulose $(25,50$, and $100 \mathrm{mmol} / \mathrm{l}$ ) led to sequential increases in the amount of $\gamma$-aminobutyric acid like activity produced from $0.27(n=2)$ to $0.37(n=2)$ and $0.43 \mathrm{~mol} /$ bacterium $\times 10^{-15}(\mathrm{n}=2)$ respectively. Lactulose at a concentration of $100 \mathrm{mmol} / \mathrm{l}$ was used in further studies.

Figure 2 shows the concentration of $\gamma$ aminobutyric acid like activity $(\mu \mathrm{mol} / \mathrm{l})$ under aerobic and anaerobic conditions after the addition of protein and lactulose. Under aerobic conditions there was a significant increase from mean (SEM), 104 (11) (E coli alone) to 145 (10) and $286(4) \mu \mathrm{mol} / \mathrm{l}$ after culture in media containing blood $(\mathrm{p}<0.05)$ and haemoglobin $(\mathrm{p}<0.001)$ respectively, and 327 (8) $\mu \mathrm{mol} / \mathrm{l}$ when albumin was added to the culture medium $(p<0.001)$. There was no significant increase with the addition of lactulose alone (134 (9.3) $\mu \mathrm{mol} / \mathrm{l}, \mathrm{p}=\mathrm{NS})$, but after the addition of lactulose and albumin to the medium the amount produced $(272(11.9) \mu \mathrm{mol} / \mathrm{l})$ was significantly less than that produced by albumin alone $(p<0.01)$. When the results were expressed as the amount of $\gamma$-aminobutyric acid like activity produced per bacterium (Table II), there was an increase from $0.26(0.01) \mathrm{mol} / \mathrm{bacterium} \times 10^{-15}$ by $E$ coli alone to $0.37(0.03)$ with the addition of blood $(\mathrm{p}<0.05), 0.39(0.06)$ with lactulose $(\mathrm{p}<0.05), \quad 1.65 \quad(0.27)$ with haemoglobin $(\mathrm{p}<0.001)$, and $0.88(0.08) \mathrm{mol}$ with albumin $(\mathrm{p}<0.001)$. However, the addition of lactulose 


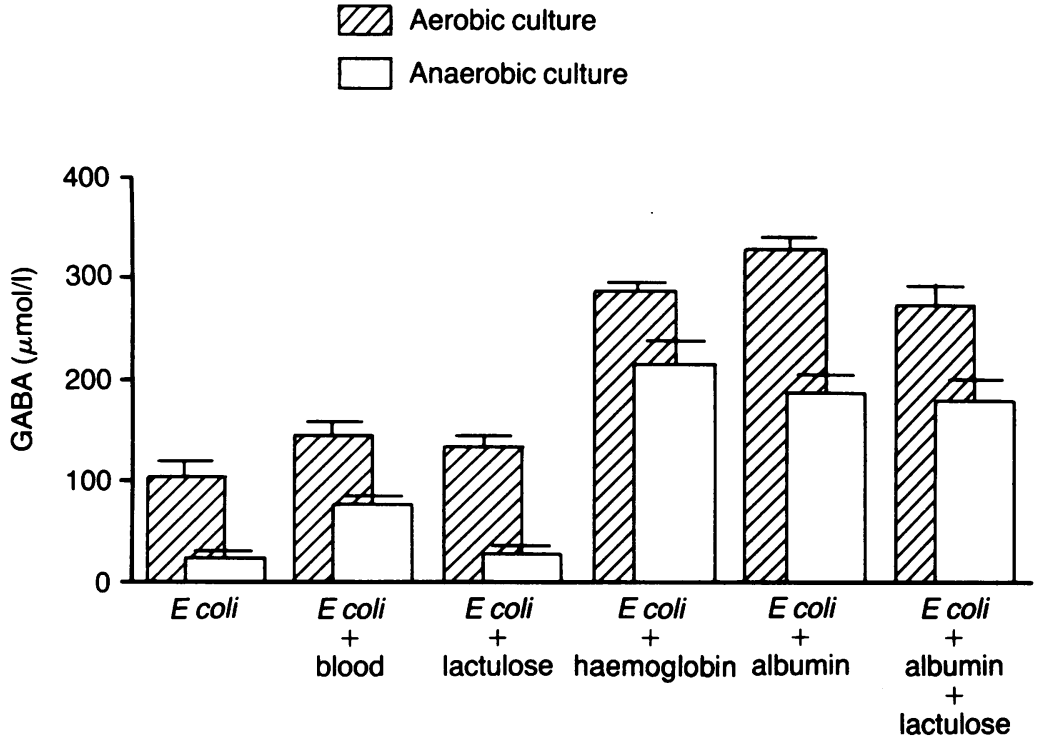

Figure 2: Concentration of $\gamma$-aminobutyric acid (GABA) like activity after culture of Escherichia coli with and without (control) the addition of whole blood, lactulose, haemoglobin, albumin, and albumin and lactulose. The results are expressed as $\mu$ molll culture medium. All values were significantly different from $\mathrm{E}$ coli alone except for $\mathrm{E}$ coli plus lactulose.
TABLE II $\gamma$-aminobutyric acid production expressed as mol bacterium (Values mean (SEM))

\begin{tabular}{|c|c|c|}
\hline & $\begin{array}{l}\text { Aerobic culture } \\
(\text { mollbacterium } \\
\left.\times 10^{-15}\right)\end{array}$ & $\begin{array}{l}\text { Anaerobic culture } \\
(\text { mollbacterium } \\
\left.\times 10^{-15}\right)\end{array}$ \\
\hline $\begin{array}{l}\text { Escherichia coli } \\
E \text { coli+blood } \\
E \text { coli+ Hb } \\
E \text { coli+lactulose (lact) } \\
E \text { coli+ albumin (alb) } \\
E \text { coli+ alb+lact }\end{array}$ & $\begin{array}{l}0.26(0.01)(n=6) \\
0.37(0.03)(n=4) \star \\
1.65(0.27)(n=4) \dagger \\
0.39(0.06)(n=6)^{\star} \\
0.88(0.08)(n=5) \dagger \\
0.86(0.16)(n=6) \dagger\end{array}$ & $\begin{array}{c}9 \cdot 7(1 \cdot 9)(n=4) \\
3 \cdot 2(0 \cdot 6)(n=4) \\
132 \cdot 8(28 \cdot 9)(n=4) \dagger \\
14 \cdot 9(6 \cdot 9)(n=4) \\
45 \cdot 5(8 \cdot 3)(n=4) \dagger \\
46 \cdot 4(6 \cdot 9)(n=4) \dagger\end{array}$ \\
\hline
\end{tabular}

${ }^{\star} \mathrm{p}<0.05,+\mathrm{p}<0.01$ compared with $E$ coli alone.

For incubation conditions see materials and methods.

the addition of lactulose alone (28 (4) $\mu \mathrm{mol} / \mathrm{l})$ showed no significant effect and the addition of lactulose and albumin (179 (16) $\mu \mathrm{mol} / \mathrm{l})$ was not significantly different from that found with albumin alone.

When the results were expressed as $\gamma$ aminobutyric acid equivalent per bacterium (Table II) there were noticeable differences compared with the values obtained under aerobic conditions. The production of $\gamma$ aminobutyric acid like activity $\left(\mathrm{mol} \times 10^{-15}\right)$ was 9.7 (1.9) by $E$ coli alone, $14.9(6.9)$ with lactulose (NS), $45 \cdot 5(8.3)$ with albumin $(\mathrm{p}<0.01), 46.4$ (6.9) with albumin and lactulose $(\mathrm{p}<0.01), 132.8$ $(28.9)$ with haemoglobin $(\mathrm{p}<0.01)$ and $3 \cdot 2(0.6)$ with the addition of blood. Again, the difference between the values obtained from media containing albumin alone and albumin and lactulose were not significant.

PRODUCTION OF $\gamma$-AMINOBUTYRIC ACID LIKE ACTIVITY UNDER ANAEROBIC CONDITIONS The concentrations of $\gamma$-aminobutyric acid like activity found after incubation under anaerobic conditions, with and without the addition of lactulose and protein, are shown in Figure 2. In general, $\gamma$-aminobutyric acid like activity was less than that obtained under aerobic conditions. There was a similar increase in activity from mean (SEM) 23 (2) $\mu \mathrm{mol} / \mathrm{l}$ by $E$ coli alone to 77 (3) $\mu \mathrm{mol} / \mathrm{l}$ after the addition of blood $(\mathrm{p}<0.001)$, to $186(13)$ with albumin $(\mathrm{p}<0.001)$ and $214(20)$ $\mu \mathrm{mol} / 1$ with haemoglobin $(\mathrm{p}<0.001)$. Again

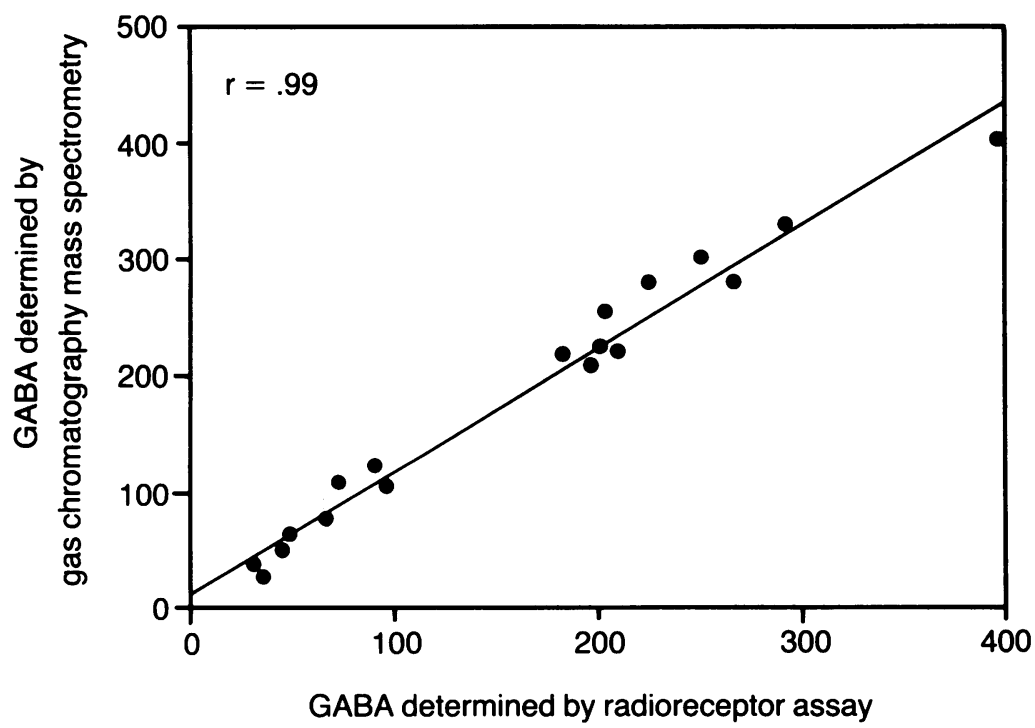

Figure 3: $\gamma$-aminobutyric acid from aerobic Escherichia coli cultures measured by the radioreceptor assay and gas chromatography mass spectrometry ( $\mu$ mol/l; correlation coefficient $r=0.99)$.
$\gamma$-AMINOBUTYRIC ACID CONCENTRATIONS MEASURED BY RADIORECEPTOR ASSAY COMPARED WITH GAS CHROMATOGRAPHY MASS SPECTROPHOTOMETRY

The results obtained by both the radioreceptor assay and gas chromatography mass spectrophotometry are shown in Figure 3. There was excellent correlation between the values obtained by the two techniques $(r=0.99)$.

\section{EFFECT OF INCUBATION ON LACTULOSE} CONCENTRATION

The concentration of lactulose after incubation of $E$ coli with lactulose alone under aerobic and from the starting concentration. In the presence of albumin and lactulose, however, the concentrations after 30 hours' incubation in duplicate cultures were 47 and $53 \mathrm{mmol} / \mathrm{l}$ under aerobic conditions and 40 and $40 \mathrm{mmol} / \mathrm{l}$ under anaerobic conditions, indicating lactulose utilisation in the presence of protein.

\section{Discussion}

Lactulose has long been used in the management of patients with hepatic encephalopathy,' and more recently the related compound lactitol (which is more palatable) has also been shown to be effective in patients with both overt and subclinical encephalopathy. ${ }^{18} 19$ Lactulose is known to be metabolised by colonic bacteria ${ }^{20}$ and its metabolism results in the reduction of colonic $\mathrm{pH}$ and alteration in colonic volatile fatty acids. ${ }^{21}$ These do not, however, explain directly anaerobic conditions did not change significantly 
its beneficial effect in the management of this condition.

In our hands, the four different liquid culture media used in previous studies ${ }^{10}$ gave high background counts of $\gamma$-aminobutyric acid, making them unsuitable for studying changes in activity during culture. The non-organic media used gave minimal background activity, although compared with Minuk's findings, ${ }^{22}$ the production of $\gamma$-aminobutyric acid by $E$ coli was delayed, reaching its maximal stationary value after 30 hours of incubation.

The addition of blood, haemoglobin, albumin, and lactulose to the culture media increased the production of $\gamma$-aminobutyric acid by $E$ coli under aerobic conditions. Under anaerobic conditions, although less $\gamma$ aminobutyric acid was produced, its production increased by more than $700 \%$ after the addition of albumin and haemoglobin. When the amount of $\gamma$-aminobutyric acid produced was related to the luxurience of bacterial growth, anaerobic production was at least 30 times greater than aerobic culture and 50 and 100 times higher after the addition of albumin and haemoglobin.

In addition, the apparent attenuation of $\gamma$ aminobutyric acid production by the addition of lactulose to albumin in the culture medium under aerobic conditions was not seen under anaerobic conditions or when production was related to the luxurience of bacterial growth. This cannot be explained by the lack of lactulose metabolism by $E$ coli since its concentration was found to be reduced by 50 to $60 \%$ at the end of culture period.

The concentrations of blood, albumin, and lactulose were chosen to cover the range of protein and lactulose concentrations likely to be found in the colon in patients with hepatic encephalopathy and are comparable with the concentrations used in previous studies ${ }^{4}$ which showed an effect on bacterial metabolism. However, in vivo studies by Conn et $\mathrm{ll}^{23}$ showed no quantitative effect by lactulose on the colonic flora in normal subjects or patients with liver cirrhosis.

There was excellent correlation between values obtained by the radioreceptor assay and by gas chromatography mass spectrophotometry. This confirms that the substance produced by $E$ coli is true $\gamma$-aminobutyric acid and also confirms the usefulness of the simpler radioreceptor assay.

This study shows that the colon is a potential source of true $\gamma$-aminobutyric acid and that protein significantly enhances its production by faecal bacteria. These data suggest that lactulose does not exert its beneficial effect by attenuating bacterial $\gamma$-aminobutyric acid production. This does not necessarily militate against $\gamma$ aminobutyric acid having a role in the mediation of hepatic encephalopathy as little is known about its utilisation within the colon by other bacteria or its absorption, both of which could be affected by treatment with lactulose.

1 Bircher J, Muller J, Guggenheim P, Haemmerli UP. Treatment of chronic portal-systemic encephalopathy with lactulose. Lancet 1966; i: 890-3.

2 Conn HO, Lieberthal MM. The hepatic coma syndromes and lactulose. Baltimore: Williams and Wilkins, 1979.

3 Conn HO. Leevy CM, Vlahcevic ZR, et al. Comparison of lactulose and neomycin in the treatment of chronic portal systemic encephalopathy. Gastroenterology 1977; 72: 573-83.

4 Mortensen PB, Rasmussen HS, Holtug K. Lactulose detoxifies in vitro short-chain fatty acid production in colonic contents induced by blood: implications for hepatic coma. Gastroenterology 1988; 94: 750-4.

5 Schafer DF, Jones EA. Hepatic encephalopathy and the $\gamma$ aminobutyric acid neurotransmitter system. Lancet 1982; 18-20.

6 Ferenci P, Schafer DF, Klenberger G, Hoofnagle JH, Jones EA. Serum levels of gamma aminobutyric acid-like activity and acute and chronic hepatocellular disease. Lancet 1983; ii: $811-4$.

7 Minuk GY, Winder A, Burgess ED, Sarjeant EJ. Serum gamma aminobutyric acid (GABA) levels in patients with hepatic encephalopathy. Hepatogastroenterology 1985; 32: $171-4$.

8 Schafer DF, Thakur AK, Jones EA. Acute hepatic coma and inhibitory neurotransmission: increase in $\gamma$-amino butyric acid levels in plasma and receptors in brain. Gastroenterology acid levels in plasn

9 Bassett ML, Mullen KD, Scholz B, Fenstermacher JD, Jones EA. Increased brain uptake of $\gamma$-aminobutyric acid in a rabbit model of hepatic encephalopathy. Gastroenterology 1990; 98: 747-57

10 Schafer DF, Fowler JM, Jones EA. Colonic bacteria: a source of gamma aminobutyric acid in blood. Proc Soc Exp Biol Med 1981; 167: 301-3.

11 Van Berlo CLH, DeJonge HR, Van den Bogaard AEJM, Van Elik HMH, Janssen MA, Soeters PB. Gamma-aminobutyric acid production in small and large intestine of normal and germ-free Wistar rats. Gastroenterology 1987; 93: 472-9.

12 Miles AA, Misra SS. The estimation of the bactericidal power of the blood. F Hyg (Camb) 1938; 38: 732-48.

13 Laker MF. Estimation of disaccharides in plasma and urine by gas-liquid chromatography. $\mathcal{f}$ Chromatogr 1979; 163: 9-18.

14 Enna SJ, Snyder SH. Properties of gamma amino butyric acid (GABA) receptor binding in rat brain synaptic membrane fractions. Brain Res 1975; 600: 81-97.

15 Ferkany JW, Smith LA, Siefort WE, Caprioli RM, Enna SJ. Measurement of gamma amino butyric acid (GABA) in blood. Life Sci 1978; 22: 2121-8.

16 Moroni F, Bianchi C, Tanganelli S, Moneti G, Beani L. The release of $\gamma$-amino butyric acid, glutamate, and acetylcholine
from striatal slices. A mass fragmentographic study. from striatal slices. A mass

17 Levy LJ, Luk J, Losowsky MS. Evidence for $\gamma$-aminobutyric acid as the inhibitor of $\gamma$-aminobutyric acid binding in the plasma of humans with liver disease and hepatic encephalopathy. Clin Sci 1987; 73: 531-4.

18 Morgan MY, Hawley KE, Stambuk D. Lactitol versus lactulose in the treatment of chronic hepatic encephalopathy. A double-blind, randomised, cross-over study. f Hepatol 1987; 4: 236-44.

19 Morgan MY, Alonso M, Stanger C. Lactitol and lactulose for the treatment of subclinical hepatic encephalopathy in cirrhotic patients. A randomised cross-over study $\mathcal{f}$ Hepatol 1989; 8: 208-17.

20 Sahota SS, Bramley PM, Menzies IS. The fermentation of lactulose by colonic bacteria. F Gen Microbiol 1972; 128: 319-25.

21 Patil DH, Westaby D, Mahida YR, et al. Comparative modes of action of lactitol and lactulose in the treatment of hepatic encephalopathy. Gut 1987; 28: 255-9.

22 Minuk GY. Gamma aminobutyric acid (GABA) production by eight common bacterial pathogens. Scand F Infect Dis 1986; 18: 465-7.

23 Conn HO, Flach MH. Effects of lactulose and lactobacillous acidophilus on the feacal flora. Am $\mathcal{F}$ Clin Nutr 1970; 23: 1588 . 